\title{
Surgical Antibiotic Prophylaxis: Incidence and Risk of Surgical Site Infection
}

\author{
Fadzwani B. ${ }^{a}$, Raha A.R..$^{a^{*}}$, Nadia M.N. ${ }^{a}$, Wan Rahiza WM. ${ }^{a}$, Razman J. ${ }^{b}$, Nordiah A.J \\ ${ }^{a}$ Department of Anaesthesiology and Intensive Care, Universiti Kebangsaan Malaysia Medical Centre \\ bepartment of Surgery, Universiti Kebangsaan Malaysia Medical Centre \\ 'Department of Microbiology and Immunology, Universiti Kebangsaan Malaysia Medical Centre
}

\section{ABSTRACT}

Introduction: This prospective cross sectional study assessed surgical antibiotic prophylaxis (SAP) practice, the incidence of surgical site infection (SSI) and its associated risks in Universiti Kebangsaan Malaysia Medical Centre. Methods: Patients for elective colorectal, hepatobiliary, upper gastrointestinal, breast and endocrine surgery, who received SAP were included and followed up until day-30 postoperatively. Types of antibiotic, preoperative-dose timing, intraoperative re-dosing and its duration were recorded. The incidence of SSI was calculated and its associated risks expressed in odds ratio. Results: Out of 166 patients recruited, 121 (72.89\%) patients received SAP preoperatively, and 91 (75.21\%) of them were prescribed the appropriate antibiotic as per our institutional guideline. Three patients who continued to receive therapeutic antibiotic postoperatively were excluded from statistical analysis. Eleven $(9.10 \%)$ patients received SAP beyond the preoperative-dose timing of 60 minutes $(\mathrm{p}=0.001)$, which was an independent risk factor for SSI (adjusted OR 4.527, 95\% Cl; 1.058-19.367, $\mathrm{p}=0.042$ ). The risk of SSI also remained in patients who continued to receive SAP beyond 24 hours (OR 4.667, $95 \% \mathrm{Cl} ; 1.527-14.259, \mathrm{p}=0.007$ ). The overall rate of SSI was $17.18 \%$. Conclusion: We found that the choice of antibiotic prescribed for SAP was in accordance to institutional guideline and the relatively high SSI incidence was similar to a recent local report. Although the number of patients receiving preoperative dose-timing of $>60$ minutes was low, it was nonetheless an independent risk factor for SSI. The postoperative continuation of SAP for more than 24 hours showed no benefit in reducing SSI.

KEYWORDS: surgical antibiotic prophylaxis, surgical site infection, wound classification.

\section{INTRODUCTION}

Surgical site infection (SSI) is a common healthcareacquired infection that requires timely surveillance. Surgical antibiotic prophylaxis (SAP) is one of the established components of SSI prevention. Most institutions have their own antibiotic recommendation for SAP. In the United States, a clinical practice guideline was published in 2013 to ensure rational, safe and effective SAP practice among clinicians. ${ }^{2}$ In institutions where guidelines are less established, SAP prescription is based

\section{Corresponding author:}

Assoc. Prof. Dr. Raha Abdul Rahman

Consultant Anaesthesiologist,

Department of Anaesthesiology and Intensive Care, Universiti Kebangsaan Malaysia Medical Centre, Jalan Yaacob Latif, Bandar Tun Razak, 56000 Cheras, Kuala Lumpur, Malaysia.

Tel No : +60391455782

Email : raha@ppukm.ukm.edu.my on common practice or experience. ${ }^{3,4}$ Surgical antibiotic prophylaxis is commonly prescribed by the surgical team, and in most instances administered by anaesthetists preoperatively. An observational survey involving five teaching centres reported poor knowledge of a standard SAP protocol among the anaesthetists. $^{5}$

A widely used World Health Organization (WHO) surgical safety checklist in 2009 suggested that antibiotic prophylaxis be administered within 60 minutes prior to surgical incision. ${ }^{6}$ However, the 2016 WHO SSI prevention guideline recommended a preoperative dose timing of less than 120 minutes, considering the half-life of the antibiotic. ${ }^{1}$ If surgical duration exceeds twice the antibiotic half-life, intraoperative re-dosing should be considered. ${ }^{7}$ The prescription of antibiotic prophylaxis up to, or exceeding 24 hours postoperatively is not uncommon. However, the Centres for Disease Control 
and Prevention (CDC) strongly recommend that SAP be discontinued after skin closure, in clean and clean-contaminated surgeries. ${ }^{8,9}$ In fact, the inappropriate extended use of SAP has raised global concern of the emergence of antibiotic resistance, in addition to resulting in financial waste. ${ }^{10}$

Universiti Kebangsaan Malaysia Medical Centre (UKMMC) had recently published a Surgical Prophylaxis Guideline (2018) for institutional use. ${ }^{11}$ It provides a guideline on the choice of antibiotic for all common surgical procedures, where a single dose of prophylactic antibiotic is administered within 120 minutes prior to surgical incision, and an additional dose if required is given, up to 24 hours postoperatively, in clean-contaminated and contaminated elective surgeries. ${ }^{11}$ It was part of the instituitional antibiotic stewardship programme which aimed to decrease financial cost, and risk of developing antibiotic resistance while improving patient outcomes. ${ }^{1,2,9,10}$ However in practice, the choice, timing and redosing of SAP depends on the attending clinician. Our instituition is a teaching center with various surgical subspecialities, comprised of clinicians and trainees with differing experience. This study was conducted before implementation of the Surgical Prophylaxis Guideline (2018), with the main objective of observing SAP practice among our clinicians following the previous Anti-infective Guideline (2012), and to determine the incidence of $\mathrm{SSI}$ and its associated risks in general surgical cases under general anaesthesia.

\section{MATERIALS AND METHODS}

This prospective cross-sectional study was conducted at UKMMC following approval from the Research and Ethics Committee, Department of Anaesthesiology \& Intensive Care, and the Medical Research \& Ethics Committee, UKMMC. Patients aged over 18 years, who underwent elective hepatobiliary, colorectal, breast, endocrine, and upper gastrointestinal surgeries, from $1^{\text {st }}$ February to $31^{\text {st }}$ October 2017 were included. Exclusion criteria include those patients on pre-existing therapeutic antibiotics, patients for emergency procedures and paediatric patients. Patients were recruited during the premedication round and consent was obtained. The patient's age, American Society of Anesthesiologist (ASA) physical status, diagnosis, comorbidities, type of surgery, and antibiotic for SAP were recorded.
In the operation theatre (OT), SAP prepared by the surgeon was administered parenterally by the anaesthetist before anaesthesia induction. The duration between antibiotic administration to surgical incision was defined as the preoperativedose timing. This was verified by the OT nurse and recorded in the surgical checklist. The WHO surgical safety checklist (2009) recommends antibiotic prophylaxis administration within 60 minutes prior to skin incision. ${ }^{6}$ The dosage and time of antibiotic administration, and any intraoperative antibiotic redosing were recorded. Surgical wound classification based on the CDC guideline ${ }^{12}$, and duration of SAP was reaffirmed by the surgeon at surgical completion. Surgical duration and intraoperative complications such as bleeding in excess of 2 litres, or persistent hypotension (mean arterial pressure < $65 \mathrm{mmHg}$ ) requiring treatment, were recorded.

The patients were followed up on day-3 postoperatively. The type, dosage, duration, and reason for SAP extension where applicable, were recorded. Wound inspection was done by the surgeon, researcher or infection control nurse, and the diagnosis of SSI was based on the CDC clinical criteria. ${ }^{12}$ Both patient and care taker were advised regarding wound care prior to discharge. Patients not diagnosed with SSI on day-3 postoperatively or prior to discharge, were followed up until day-30 postoperatively in the ward, or via phone interview by the researcher if discharged. The phone interview was part of the CDC recommendation surveillance to diagnose SSI post-discharge. During conduct of this study, there was no valid assessment tool to diagnose SSI post-discharge. Interview questionnaires were particular to an institution and considered acceptable, provided the CDC criteria was used. ${ }^{12}$ Our interview questionnaire was institutionally adapted from the CDC criteria.

Estimated sample size for this study of a population $<10$ 000, was calculated according to Kish L. 1965 formula; $n=(Z 1-a) 2(P(1-P) / D 2)$, where $1-a=$ Confidence interval, $P=$ Prevalence, $D=$ Absolute precision required was $\mathrm{Z1}-\mathrm{a}=\mathrm{Z}=.95=1.96$ (from $\mathrm{a}$ normal distribution table). The number of elective general surgical cases under general anaesthesia in UKMMC in 2015 was 389. Allowing for a confidence interval of $95 \%$, an absolute precision of $5 \%$, and predicted prevalence of $10 \%$ of the population developing SSI, the calculated sample size was 138. 
We recruited 166 samples allowing for a 20\% drop out. Data was analysed using the SPSS 20.0 statistical package. Patient characteristics and variables associated with SAP practice were examined. The association between these variables and the occurrence of SSI was assessed using the Chi-square and Fisher exact test. The crude odds ratio (OR) and corresponding $95 \%$ confidence interval (CI) assessed the degree of association. Multivariate logistic regression was applied to obtain the adjusted OR with the respective $95 \% \mathrm{Cl}$. Variables tested for inclusion in the multivariate model were those significantly associated with SSI. A p value $\leq 0.05$ was considered statistically significant.

\section{RESULTS}

Of the 166 recruited patients, 121 (74.23\%) patients received antibiotic prior to surgery as SAP, of which $80(66.12 \%)$ of them were classified as having cleancontaminated surgical wounds and 38 (31.40\%) as clean surgical wounds. Three (2.48\%) patients with contaminated surgical wounds continued to receive antibiotic as treatment postoperatively, thus were excluded from further analysis. Among the 163 recruited patients, 45 (27.61\%) had upper gastrointestinal, 40 (24.54\%) hepatobiliary, 40 (24.54\%) colorectal, and 38 (23.31\%) breast or endocrine surgery. All were successfully followed up as per the research protocol.

Table 1 shows prescribed antibiotics, the most commonly prescribed being the broad spectrum penicillin, amoxicillin/clavulanate (75.21\%), followed by the combination of cefoperazone and metronidazole (14.87\%). Patients allergic to the penicillin and cephalosporin groups were given fluoroquinolones i.e ciprofloxacin. The antibiotic prescribed was in accordance to our institution's guideline. Table 2 shows that most patients (65.64\%) received SAP within the preoperative-dose timing of 60 minutes. The 5 patients who received SAP beyond the 60 minutes had increased risk of developing SSI (OR 4.120, 95\% Cl; 1.134-14.974, $\mathrm{p}=0.032$ ). Subanalysis showed that these 5 patients had wide local excision for breast carcinoma, laparoscopic excision of oesophageal carcinoma, Whipple's procedure for duodenal carcinoma, right hemicolectomy for colon carcinoma and laparoscopic cholecystectomy.
Table 1. Type of antibiotic used as surgical prophylaxis preoperatively.

\begin{tabular}{lc}
\hline \multicolumn{1}{c}{ Type of Antibiotic } & $\begin{array}{c}\text { No. of cases, } \\
\mathrm{n}(\%)\end{array}$ \\
\hline Amoxicillin/Clavulanate & $91(75.21)$ \\
Cefoperazone and Metronidazole & $18(14.87)$ \\
Metronidazole & $4(3.30)$ \\
Cefuroxime & $2(1.65)$ \\
Ceftriaxone & $2(1.65)$ \\
Cefotaxime & $1(0.83)$ \\
Cefuroxime and Metronidazole & $1(0.83)$ \\
Ciprofloxacin & $1(0.83)$ \\
Ciprofloxacin and Metronidazole & $1(0.83)$ \\
Total & $121(100 \%)$ \\
\hline
\end{tabular}

Thirty-one (19.02\%) patients had surgical duration exceeding four hours, which corresponded to two half-lives of the antibiotics used. ${ }^{11}$ Among the 31 patients, $3(9.68 \%)$ received re-dosing of SAP intraoperatively, from which $2(66.67 \%)$ developed SSI. Among the remaining $28(90.32 \%)$ patients who did not receive intraoperative re-dosing, 11 (39.29\%) developed SSI $(p=0.558)$. However, the incidence and risk of SSI in patients who did not receive intra-operative re-dosing was comparable to those who did (OR 0.324, 95\% Cl; 0.026-4.011, $\mathrm{p}=0.380$ ) (Table 2). Sixty-three (53.38\%) patients had prophylactic antibiotic extended postoperatively. Eighteen $(28.57 \%)$ of them developed SSI, and this made up $64.28 \%$ of the total number of SSIs reported. Further univariate analysis showed that patients who received SAP beyond 24 hours had significant risk for SSI (OR 4.667, 95\% Cl; 1.527-14.259, $\mathrm{p}=0.007$ ) (Table 2).

In summary, $28(17.2 \%)$ patients developed SSI, of which 5 did not receive SAP. Sixteen patients (57.14\%) were diagnosed with SSI after discharge. Table 3 shows that the risks of developing SSI included age $>65$ years, ASA II and III physical status, malignancy, open surgical approach and clean contaminated wound surgery $(p<0.05)$. Patients with malignancy, who comprised half the number of SSI cases (14 patients), showed increased risk of SSI (OR 3.219, $95 \% \mathrm{Cl} ; 1.389-7.458, \mathrm{p}=0.006$ ). Based on wound classification, the risk of SSI was lower $(7.25 \%)$ in clean, than in clean-contaminated wound $(24.47 \%)$ surgery $(p=0.004)$. Five patients, despite catergorised as clean wound surgery hence did not receive SAP, also developed SSI but it was not a significant finding, $p=0.146$. 
Table 2. Surgical antimicrobial prophylaxis practice: preoperative-dose timing, intraoperative re-dosing and extended use postoperatively.

\begin{tabular}{|c|c|c|c|c|c|c|}
\hline Variables & $\begin{array}{c}\text { Without SST } \\
\text { n(\%) }\end{array}$ & $\begin{array}{l}\text { With SST } \\
\text { n(\%) }\end{array}$ & p-value & $\begin{array}{l}\text { Odd } \\
\text { ratio } \\
\text { (OR) }\end{array}$ & $\begin{array}{c}95 \% \\
\text { Confidence } \\
\text { Interval }\end{array}$ & $p$-value \\
\hline Preoperative-dose timing* & & & 0.032 & & & \\
\hline$\leq 60$ minutes, $\mathrm{n}=107$ & $89(83.18)$ & $18(16.82)$ & & 1.000 & & \\
\hline$>60$ minutes, $n=11$ & $6(54.55)$ & $5(45.45)$ & & 4.120 & $1.134-14.974$ & 0.032 \\
\hline Not given, $n=45$ & $40(88.89)$ & $5(11.11)$ & & 0.618 & $0.214-1.782$ & 0.618 \\
\hline Intraoperative & & & 0.558 & & & \\
\hline \multicolumn{7}{|l|}{ Re-dosing** } \\
\hline Yes, n=3 & $1(33.33)$ & $2(66.67)$ & & 1.000 & & \\
\hline No, $n=28$ & $17(60.71)$ & $11(39.29)$ & & 0.324 & $0.026-4.011$ & 0.380 \\
\hline Dose of SAP; & & & 0.016 & & & \\
\hline Single dose, $n=55$ & $50(90.91)$ & $5(9.09)$ & & 1.000 & & \\
\hline \multicolumn{7}{|l|}{ Extended use ${ }^{* * *}:$} \\
\hline Up to $24 \mathrm{hrs}, \mathrm{n}=19$ & $15(78.95)$ & $4(21.05)$ & & 2.667 & $0.634-11.208$ & 0.181 \\
\hline$\geq 24$ hours, $n=44$ & $30(68.18) 40$ & $14(31.82)$ & & 4.667 & $1.527-14.259$ & 0.007 \\
\hline Not given, $n=45$ & $(88.89)$ & $5(11.11)$ & & 1.250 & $0.338-4.621$ & 0.738 \\
\hline
\end{tabular}

${ }^{a} p$-value for Chi Square and Fisher exact test

${ }^{b} p$-value for univariate analysis

*Antibiotic prophylaxis given prior to surgical incision

** Surgical duration more than four hours

***Antibiotic prophylaxis continued after surgical closure

Following a multivariate logistic regression model analysis, we found that independent risk factors for SSI were preoperative-dose timing of SAP beyond 60 minutes (adjusted OR 4.527, 95\% Cl; 1.058-19.367, $\mathrm{p}=0.042$ ), open surgical approach (adjusted OR 3.041, $95 \% \mathrm{Cl} ; 1.104-5.381, \mathrm{p}=0.031$ ) and clean contaminated wound surgeries (adjusted OR 3.866, $95 \% \mathrm{Cl} ; 1.171-12.757, \mathrm{p}=0.026)$. The confounding factors were extended dose of SAP, age $>65$ years, ASA II and III physical status, diabetic patients and malignancy. The incidence of SSI was comparable between patients who had undergone hepatobiliary $(30.00 \%)$ and colorectal $(27.50 \%)$ surgery (Table 4$)$. In the former, SSI was higher with the open surgical approach, $\mathrm{p}=0.001$. In contrast, there was no difference in SSI between patients who underwent minimally invasive and open technique colorectal surgery, $p=0.385$.

\section{DISCUSSION}

Amoxicillin/clavulanate was the most frequently prescribed SAP for general surgical procedures, as per our institution's recommendation. A combined therapy of a second or third generation cephalosporin, and metronidazole were prescribed for cases which required aerobic and anaerobic coverage. The WHO's 'Global Guidelines for The Prevention of Surgical Site Infection 2016', and the 'CDC Prevention Guideline for The Prevention of
Surgical Site Infection 2017' had no specific recommendation on the type and dosage of antibiotic for SAP perioperatively. ${ }^{1,9}$ Most institutions have their own recommendation for SAP depending on the type of surgery, institution's antibiogram and availability of antibiotic choices. However, many guidelines recommend first generation cephalosporin i.e cefazolin combination with metronidazole, or second generation cephalosporin as monotherapy for SAP in most general surgical procedures. ${ }^{2,11,13,15}$

In our study, more than two-third of surgical operations were prescribed SAP. The optimum effect of prophylactic antibiotic is achieved when its therapeutic concentration is above the minimum inhibitory concentration (MIC), and antibiotic concentration in both plasma and interstitial tissue around the surgical wound is in equilibrium, until skin closure. ${ }^{16}$ The time and dose of preoperative SAP administration are crucial to achieve the MIC for the targeted pathogens in a particular surgery. This can be achieved by using an integrated PK-PD model to guide SAP practice perioperatively. ${ }^{15}$ We found that preoperative-dose timing of more than 60 minutes was an independent risk factor to the development of SSI. Bratzler et al. suggested that the optimal time for preoperative SAP administration was within 60 minutes before surgical incision rather than at induction of anaesthesia. ${ }^{2}$ However, the ideal practice of SAP differs between time-dependent 
Table 3. Patient and surgical factors for SSI; a univariate analysis.

\begin{tabular}{|c|c|c|c|c|c|c|}
\hline Variables & $\begin{array}{l}\text { Without SST } \\
N(\%)=135 \\
(82.82)\end{array}$ & $\begin{array}{l}\text { With SST } \\
N(\%)=28 \\
(17.18)\end{array}$ & $p$-value ${ }^{a}$ & $\begin{array}{l}\text { Odd } \\
\text { ratio, } \\
\text { (OR) }\end{array}$ & $\begin{array}{l}95 \% \text { Confidence } \\
\text { Interval }\end{array}$ & $p$-value \\
\hline Age, years & & & 0.033 & & & \\
\hline$\leq 35$ & $32(91.43)$ & $3(8.57)$ & & 1.000 & & \\
\hline $36-64$ & $75(85.23)$ & $13(14.77)$ & & 1.849 & $0.493-6.934$ & \\
\hline$\geq 65$ & $28(70.00)$ & $12(30.00)$ & & 4.571 & $1.170-17.865$ & 0.029 \\
\hline BMI, $\mathrm{kg} / \mathrm{m}^{2}$ & & & 0.130 & & & \\
\hline$\leq 29$ & $86(79.63)$ & $22(20.37)$ & & 1.000 & & \\
\hline$\geq 30$ & 49(89.09) & 6(10.91) & & 0.479 & $0.182-1.261$ & 0.136 \\
\hline ASA & & & 0.021 & & & \\
\hline I & $66(90.41)$ & $7(9.59)$ & & 1.000 & & \\
\hline II \& III & $69(76.67)$ & $21(23.33)$ & & 2.870 & $1.144-7.197$ & 0.025 \\
\hline Gender & & & 0.642 & & & \\
\hline male & 61(81.33) & $14(18.67)$ & & 1.000 & & \\
\hline female & 74(84.09) & $14(15.91)$ & & 0.824 & $0.365-1.862$ & 0.642 \\
\hline \multicolumn{7}{|l|}{ Comorbidities } \\
\hline Diabetes & & & 0.047 & & & \\
\hline No & $102(86.44)$ & $16(13.56)$ & & 1.000 & & \\
\hline Yes & $33(73.33)$ & $12(26.67)$ & & 2.318 & $0.996-5.397$ & 0.051 \\
\hline Anaemia & & & 0.548 & & & \\
\hline No & $129(83.23)$ & $26(16.77)$ & & 1.000 & & \\
\hline Yes & $6(75.00)$ & $2(25.00)$ & & 1.654 & $0.316-8.653$ & 0.551 \\
\hline Malignancy & & & 0.005 & & & \\
\hline No & $103(88.03)$ & $14(11.97)$ & & 1.000 & & \\
\hline Yes & $32(69.57)$ & $14(30.43)$ & & 3.219 & $1.389-7.458$ & 0.006 \\
\hline Smoking & & & 0.817 & & & \\
\hline No & 104(83.20) & $21(76.80)$ & & 1.000 & & \\
\hline Yes & $31(81.6)$ & $7(18.4)$ & & 1.118 & $0.435-2.876$ & 0.817 \\
\hline \multicolumn{7}{|l|}{ Length of hospital stay } \\
\hline preoperatively & & & 0.671 & & & \\
\hline$\leq 1$ day & $97(83.60)$ & $19(16.40)$ & & 1.000 & & \\
\hline$\geq 2$ days & $38(81.58)$ & $9(18.42)$ & & 1.209 & $0.503-2.907$ & 0.671 \\
\hline Surgical approach & & & 0.011 & & & \\
\hline Minimally invasive & $78(89.66)$ & $9(10.34)$ & & 1.000 & & \\
\hline Open & $56(74.67)$ & $19(25.33)$ & & 2.978 & $1.255-7.065$ & 0.013 \\
\hline Wound Classification & & & 0.004 & & & \\
\hline Clean & $64(92.75)$ & $5(7.25)$ & & 1.000 & & \\
\hline Clean-contaminated & $71(75.53)$ & $23(24.47)$ & & 4.146 & $1.489-11.550$ & 0.007 \\
\hline \multicolumn{7}{|l|}{ Intraoperative } \\
\hline \multicolumn{7}{|l|}{ Complications } \\
\hline Hypotension & & & 0.315 & & & \\
\hline No & $134(83.23)$ & $27(16.77)$ & & 1.000 & & \\
\hline Yes & $1(50.00)$ & $1(50.00)$ & & 4.963 & $0.301-81.816$ & 0.263 \\
\hline Bleeding $>2.0 \mathrm{~L}$ & & & 1.000 & & & \\
\hline No & $133(82.61)$ & 28(17.39) & & - & - & \\
\hline Yes & $2(100)$ & $0(0)$ & & - & - & - \\
\hline
\end{tabular}

Abbreviations; BMI, Body Mass Index, ASA, American Society of Anaesthesiology ${ }^{a} p$-value for Chi Square and Fisher exact test

${ }^{\mathrm{b}} p$-value for univariate analysis

(i.e. cefazolin, cefoxitin, ceftriaxone, ertapenem, clindamycin) and concentration-dependent (i.e. gentamicin, levofloxacin, metronidazole) antibiotics. $^{16} \quad$ For concentration-dependent incision. ${ }^{1,2}$ antibiotics such as metronidazole, which require administration as an infusion, it is acceptable for the drug to be given within 120 minutes before surgical 
Table 4. Risk factors for SSI among surgical specialties based on surgical approach and wound classification.

\begin{tabular}{|c|c|c|c|c|c|c|}
\hline \multirow{2}{*}{$\begin{array}{l}\text { Surgery Related Risk } \\
\text { factors, } \\
\text { n (\%) }\end{array}$} & \multicolumn{3}{|c|}{$\begin{array}{l}\text { Hepatobiliary, } \\
\qquad \mathrm{N}=40\end{array}$} & \multicolumn{3}{|c|}{$\begin{array}{l}\text { Colorectal, } \\
\mathrm{N}=40\end{array}$} \\
\hline & $\begin{array}{l}\text { With-out } \\
\text { SSI, } n=28\end{array}$ & $\begin{array}{c}\text { With SSI, } \\
n=12\end{array}$ & $p$-value & $\begin{array}{l}\text { With-out } \\
\text { SSI, } n=29\end{array}$ & $\begin{array}{c}\text { With SSI, } \\
n=11\end{array}$ & $p$-value \\
\hline Wound Class & & & - & & & - \\
\hline $\begin{array}{l}\text { Clean } \\
\text { Clean-contaminated }\end{array}$ & $\begin{array}{c}0 \\
28(70.00)\end{array}$ & $\begin{array}{c}0 \\
12(30.00)\end{array}$ & & $\begin{array}{c}0 \\
29(72.50)\end{array}$ & $\begin{array}{c}0 \\
11(27.50)\end{array}$ & \\
\hline Surgical Approach & & & 0.001 & & & 0.385 \\
\hline $\begin{array}{l}\text { Minimally Invasive } \\
\text { Open }\end{array}$ & $\begin{array}{l}20(90.91) \\
8(44.44)\end{array}$ & $\begin{array}{c}2(9.09) \\
10(55.56)\end{array}$ & & $\begin{array}{l}15(78.95) \\
14(66.67)\end{array}$ & $\begin{array}{l}4(21.05) \\
7(33.33)\end{array}$ & \\
\hline \multicolumn{7}{|l|}{ Cont' } \\
\hline \multirow{2}{*}{$\begin{array}{l}\text { Surgery Related Risk } \\
\text { factors, } \\
\text { n (\%) }\end{array}$} & \multicolumn{3}{|c|}{$\begin{array}{l}\text { Upper Gastrointestinal, } \\
\qquad \mathrm{N}=45\end{array}$} & \multicolumn{3}{|c|}{$\begin{array}{l}\text { Breast and Endocrine, } \\
\qquad N=38\end{array}$} \\
\hline & $\begin{array}{l}\text { With-out } \\
\text { SSI, } n=42\end{array}$ & With SSI, $\mathrm{n}=3$ & $p$-value & $\begin{array}{l}\text { With-out } \\
\text { SSI, } n=36\end{array}$ & With SSI, n=2 & p-value \\
\hline Wound Class & & & 0.280 & & & 0.732 \\
\hline $\begin{array}{l}\text { Clean } \\
\text { Clean-contaminated }\end{array}$ & $\begin{array}{l}30(90.91) \\
12(100)\end{array}$ & $\begin{array}{c}3(90.91) \\
0\end{array}$ & & $\begin{array}{c}34(94.44) \\
2(100)\end{array}$ & $\begin{array}{c}2(5.56) \\
0\end{array}$ & \\
\hline Surgical Approach & & & 0.787 & & & 0.671 \\
\hline $\begin{array}{l}\text { Minimally Invasive } \\
\text { Open }\end{array}$ & $\begin{array}{l}41(93.18) \\
1(100)\end{array}$ & $\begin{array}{c}3(6.82) \\
0\end{array}$ & & $\begin{array}{c}3(100) \\
33(94.29)\end{array}$ & $\begin{array}{c}0 \\
2(5.71)\end{array}$ & \\
\hline
\end{tabular}

In addition to the optimal timing of preoperative SAP, guidelines, recommend a single dose of SAP for all re-dosing may be needed to maintain the therapeutic surgeries. ${ }^{1,2,9}$ In fact, the inappropriate extended use concentration above the MIC throughout surgery. ${ }^{7,11} \mathrm{~A}$ of SAP has been associated with the emergence of recent cohort study demonstrated that failure to re- antibiotic resistance, in addition to increased cost of dose a prophylactic antibiotic during long operations hospitalisation. ${ }^{10}$

i.e exceeding two half-lives of the antibiotic, was associated with increased risk of SSI. ${ }^{17}$ In our study, Patient-related factors which include age, ASA three patients received intraoperative re-dosing of classification, malignancy and diabetes mellitus, amoxicillin/clavulanate as surgery was prolonged up consistently influenced the risk of SSI. ${ }^{18-20}$ Our study to 4.5 to 8 hours. However despite re-dosing, 2 of the demonstrated that malignancy, a less modifiable 3 cases still developed SSI. Surgical site infection may factor, posed the most significant risk for SSI. We have been contributed by other factors including found that patients with clean wounds developed SSI malignancy, diabetes mellitus, and open approach despite being given SAP. Further analysis showed surgery. Our study did not show a difference in risk of that these patients were obese or had breast or SSI amongst patients who received intraoperative re- oesophageal malignancies. There were also patients dosing compared to those who did not, in surgeries classified as clean contaminated wounds, with liver extending beyond four hours.

We also found that patients who had received SAP beyond 24 hours postoperatively, had higher risk for SSI, but it was not an independent risk. In most cases, no reason was documented for the extended use, and more than two third of this group of patients had surgery classified as clean wound. Prior studies and gastrointestinal malignancies, who did not receive SAP and developed SSI post operatively. A meta-analysis of breast cancer surgeries showed that preoperative chemo or radiotherapy was an independent risk for SSI. ${ }^{21}$ The effects of radiation were hypothesised to be linked exclusively to radiation-induced cell killing, leading to post radiation organ dysfunction. ${ }^{22}$ Patients with showed that surgeons extend the antibiotic malignancy and underlying immunosuppression might prescription postoperatively owing to fear of SSI or be more susceptible to this. Diabetes mellitus was due to uncertainty of the optimum postoperative SAP also found to be significantly associated with SSI, but duration. ${ }^{13}$ To date, our institution and other major was less likely to be an independent risk factor to 


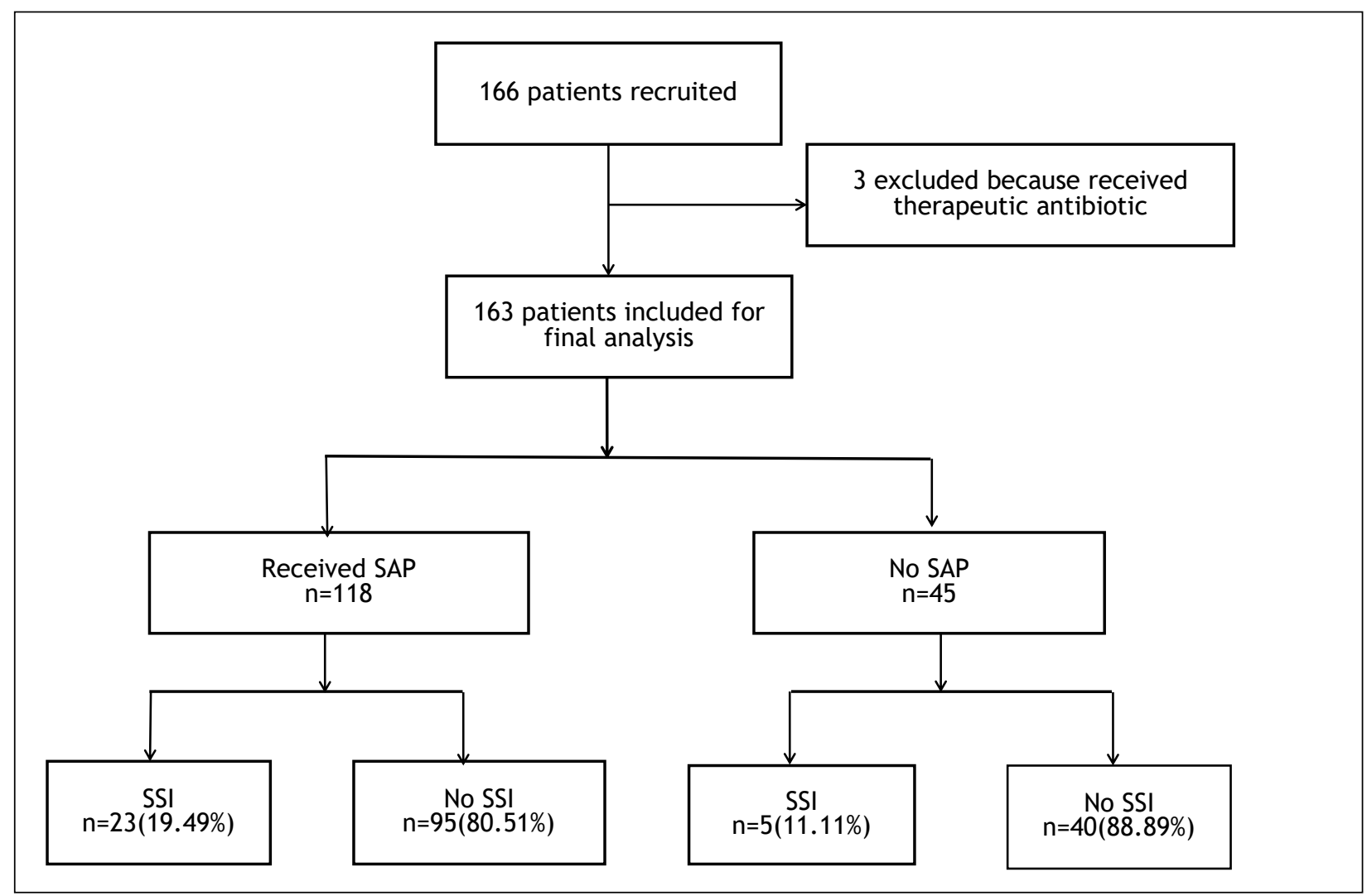

* overall incidence of SSI was 28/163=17.18\%

Figure 1. Flowchart of the overall use of antibiotic as SAP and incidence of SSI.

developing SSI. Our study involved elective surgical operations where patients' glycaemic control were likely optimised and stable prior to surgery.

In our study, the incidence of SSI for clean and clean -contaminated wound surgery, was $7.2 \%$ and $24.5 \%$ respectively. The overall SSI incidence of $17.18 \%$ was comparable to a recent reported incidence of $19.40 \%$ in elective surgeries from another tertiary hospital in Malaysia. ${ }^{23}$ It was also comparable to that reported in a university hospital in Turkey, for general surgical procedures. ${ }^{19}$ In contrast, a regional surveillance in France, involving 1730 patients for gastrointestinal surgery reported an SSI incidence of only $5.5 \%{ }^{7}$ Most of our recorded SSIs were from clean-contaminated wounds of hepatobiliary and colorectal procedures.

There was no difference in SSI incidence between open and minimally invasive procedures in all but hepatobiliary surgery. Generally, wound classification and open surgery were independent risks to developing SSI, a finding similar to previously published data. ${ }^{17,18}$ A four-point prevalence survey by Barchitta et al, reported significant reduction from $16.4 \%$ to $8.2 \%$, in the incidence of SSI, following implementation of a multimodal infection control programme involving 20 surgical departments. ${ }^{20}$ The incidence of SSI could be improved by practicing SAP following recommended guidelines. Other than the SAP protocol, perioperative management such as maintaining adequate oxygenation, normothermia, normoglycemia and normovolaemia were also recommended in preventing SSI. ${ }^{4}$

There were some limitations in our study. Firstly, the diagnosis of SSI was not clearly documented by the surgeon, hence was interpreted by the researcher as SSI based on CDC SSI criteria. Secondly, patient follow-up on day-30 postoperatively was done via phone interview, and based solely on patient feedback and that from their care takers, as opposed to patient assessment by the clinician.

The information obtained might not have been accurate and may have contributed to the high incidence $(17.2 \%)$ of SSI at our institution. Patient outcomes might have been more reliable had these patients been reviewed in the clinic or ward, rather than via phone call. Lastly, the reason for extending the duration of antibiotic prescription beyond 24 hours postoperatively was not documented, and this was assumed by the researcher as part of the SAP. 
We conclude that our clinicians complied to the recommended choice of antibiotic for SAP as per our instituitional guideline. The adherence to the preoperative-dose timing of within 60 minutes of surgical incision was important as this was shown to be an independent risk factor for SSI. On the other hand the continued administration of SAP beyond 24 hours postoperatively showed no benefit in reducing SSI.

\section{ACKNOWLEDGEMENT}

We wish to thank all the surgeons, trainees and nurses in the participating departments for their close co-operation throughout this study.

\section{Transparency Declaration}

Non to declare.

\section{REFERENCES}

1. World health Organization 2018, Preventing Surgical Site Infections: Implementation Approaches For Evidence-Based Recommendations.https://apps.who.int/iris/ bitstream/handle/10665/273154/ 9789241514385

2. Bratzler DW, Dellinger EP, Olsen KM et al. Clinical practice guidelines for antimicrobial prophylaxis in surgery. Am J Health Syst Pharm 2013; 70:195-283.

3. Afzal Khan AK, Mirshad PV, Mohammed Rafiuddin Rashed, et al. A study on the usage pattern of antimicrobial agents for the prevention of surgical site infections (SSIs) in a tertiary care teaching hospital. J Clin Diagn Res 2013; 4: 671.

4. Nagdeo N, Sonarkar R, Thombare VR et al. Effects of an educational module in rationalizing surgical prophylaxis. Indian J Surg 2015; 77: 290 $-296$.

5. Jocum J, Lowman W, Perrie $\mathrm{H}$ et al. Anaesthetists' knowledge of surgical antibiotic prophylaxis: a prospective descriptive study. South Afr J Anaesth Analg 2018; 24:97-102.

6. National Patient Safety Agency. WHO surgical safety checklist. [online] Available at http:// www.who.int/patientsafety/safesurgery/ tools_resources/SSSL_Checklist_finalJun08.pdf Accessed August 13th 2018.

7. Miliani K, L'Hériteau F, Astagneau P on behalf of the INCISO Network Study Group. Noncompliance with recommendations for the practice of antibiotic prophylaxis and risk of surgical site infection: results of a multilevel analysis from the INCISO Surveillance Network. J Antimicrob Chemother 2009; 64: 1307-1315.

8. Testa M, Stillo M, Giacomelli S et al. Appropriate use of antimicrobial prophylaxis: an observational study in 21 surgical wards. BMC surgery 2015; 15:63

9. Berríos-Torres SI, Umscheid CA, Bratzler DW et al. Centers for disease control and prevention guideline for the prevention of surgical site infection, 2017. JAMA surgery. 2017; 152:784791.

10. Ashiru-Oredope D, Sharland M, Charani E et al. Improving the quality of antibiotic prescribing in the NHS by developing a new Antimicrobial Stewardship Programme: Start Smart-Then Focus. J Antimicrob Chemother 2012; 67: 51-63.

11. Antimicrobial Stewardship Committee HCTM PPUKM. Surgical Prophylaxis Review 2018. $1^{\text {st }}$ Edition. [online] Available at https:// www.ppukm.ukm.my/farmasi/wp-content/ uploads/2018/09/PPUKM-Surgical-Prophylaxis26092018.pdf

12. National Healthcare Safety Network, Centers for Disease Control and Prevention. Surgical site infection (SSI) event, January 2017. http:/ / www.cdc.gov/nhsn/pdfs/ pscmanual/9pscssicurrent.pdf

13. Hohmann C, Eickhoff C, Radziwill R et al. Adherence to guidelines for antibiotic prophylaxis in surgery patients in German hospitals: a multicentre evaluation involving pharmacy interns. Infection 2012; 40: 131-137.

14. Poeran J, Wasserman I, Zubizarreta $\mathrm{N}$ et al. Characteristics of antibiotic prophylaxis and risk of surgical site infections in open colectomies. Dis Colon Rectum 2016; 59: 73.

15. Zelenitsky SA, Lawson C, Calic D et al. Integrated pharmacokinetic-pharmacodynamic modelling to evaluate antimicrobial prophylaxis in abdominal surgery. J Antimicrob Chemother 2016; 71: 2902-2908.

16. Asín-Prieto $E$, Rodríguez-Gascón A, Isla A. Applications of the pharmacokinetic/ pharmacodynamic (PK/PD) analysis of antimicrobial agents. J Infect Chemother 2015; 21:319-29.

17. Kasatpibal N, Whitney JD, Dellinger EP et al. Failure to Redose antibiotic prophylaxis in long surgery increases risk of surgical site infection. Surg Infect 2017; 18:474-84. 
18. Cheng K, Li J, Kong Q et al. Risk factors for surgical site infection in a teaching hospital: a prospective study of 1,138 patients.

Patient Prefer Adherence 2015; 9:1171.

19. Alp E, Altun D, Ulu-Kilic A et al. What really affects surgical site infection rates in general surgery in a developing country? J Infect Public Health 2014; 7:445-449.

20. Barchitta M, Matranga D, Quattrocchi A et al. Prevalence of surgical site infections before and after the implementation of a multimodal infection control programme. J Antimicrob Chemother 2011; 67; 749-755.

21. Xue DQ, Qian C, Yang L et al. Risk factors for surgical site infections after breast surgery: a systematic review and meta-analysis. Eur J Surg Oncol 2012; 38; 375-38.

22. Hauer-Jensen $M$, Wang J, Boerma $M$ et al. Radiation damage to the gastrointestinal tract: mechanisms, diagnosis, and management. Curr Opin Support PalliatCare 2007; 1; 23-29.

23. Tan LT, Foong $S$, Jia W, Tuan Nur' Azmah TM and Anil G. A Prospective Study of Surgical Site Infection in Elective and Emergency General Surgery in a Tertiary Public Hospital in Malaysia - A Preliminary Report. Madridge Journal of Surgery 2019; 2(1): 52-58 